\title{
Intergenerational Transmission, Self-Effort and Income Gap between Urban and Rural Youth in China
}

\author{
Junhui Han, Adu Sarfo Philip \\ School of Economics and Management, Taiyuan University of Technology, Jinzhong, China \\ Email:kjcyyk@126.com
}

How to cite this paper: Han, J. H., \& Philip, A. S. (2021). Intergenerational Transmission, Self-Effort and Income Gap between Urban and Rural Youth in China. Open Journal of Social Sciences, 9, 127-144. https://doi.org/10.4236/jss.2021.94011

Received: November 14, 2020

Accepted: April 16, 2021

Published: April 19, 2021

Copyright $\odot 2021$ by author(s) and Scientific Research Publishing Inc. This work is licensed under the Creative Commons Attribution International License (CC BY 4.0).

http://creativecommons.org/licenses/by/4.0/

\begin{abstract}
Based on the data of China Health and Nutrition Survey (CHNS) from 1991 to 2015, the effects of intergenerational income transmission and self-effort on the income gap between urban and rural youth under different quantiles were studied by using RIF's unconditional quantile regression and distribution decomposition method. The results show that the parents' income has a significant impact on the income of urban and rural youth in each quantile, and it is the main driving force to widen the income gap. By decomposing the intergenerational income elasticity, it is found that the intergenerational income of urban youth is mainly transmitted through education, while the rural youth is more reflected in the path of career transmission. Hard work has a strong impact on the income of urban and rural youth only in the middle and low quantiles, and the effect of rural youth is greater than that of urban youth. Hard work can reduce the income gap between urban and rural youth in the middle and low quantiles, but at the cost of "reverse discrimination" against rural youth.
\end{abstract}

\section{Keywords}

Intergenerational Transmission, Efforts, Urban and Rural Youth, Income Gap

\section{Introduction}

In recent years, although the change trend of the urban-rural income ratio has fluctuated in china, it basically remains at the level of 3:1. From the perspective of vertical intergenerational dimension, the income ratio of urban-rural youth is larger than that of urban-rural income gap in general even if a large number of rural youth are considered to work in cities. If all kinds of hidden income enjoyed by urban youth are included, the income gap between urban and rural "second generation" will be even larger. The excessive income gap between ur- 
ban and rural youth is not conducive to the "sustainable development" of poor families at the bottom, but also solidifies the income gap between urban and rural areas to a certain extent.

In fact, the difference of social and economic status between urban and rural residents in China is not only reflected in the living standard of "contemporary people", but also has obvious intergenerational transmission and transfer. Compared with "country folk", urban people have more advantages and "voice" in education, employment and social welfare. With the continuation of family "incense", the children of urban families will "naturally" inherit their family resource advantages. The poorer the poor, the richer the richer, and the "Matthew effect" will appear. "The People's Daily" (September 2010) and "The Liberation Daily" (December 2012) respectively took "difficulties faced by the upward mobility of the bottom of the society" and "how can we compete for father in talent recruitment", expressing concern about the intergenerational inheritance of youth economic activities. On the other hand, with the enhancement of the sense of competition, the young people work harder, and the concentrated performance is that they take the initiative to work overtime. According to the report on monitoring and investigation of migrant workers in 2016, 37.3\% of them work more than 8 hours a day and $84.4 \%$ of them work more than 44 hours a week. According to the Research Report of the Central Committee of the Communist Young League, the phenomenon of working youth working overtime is very common in large cities such as Beijing, Shanghai, Guangzhou and Shenzhen, which is higher than that in the second and third tier cities. The Chinese General Social Survey 2015 (CGSS2015) shows that migrant workers work overtime seriously, and the working hours are much longer than urban workers. Can hard work increase income and change one's destiny? This problem has aroused great concern of the whole society.

From the perspective of social ethics, the income gap caused by individual effort preference (self-responsibility factor) is easy to be accepted, while the youth income gap caused by family resources such as parents' income difference is easy to be questioned by fairness and justice. To what extent is the income gap between urban and rural youth caused by intergenerational transmission? Is there any difference in the intergenerational income transmission path between urban and rural youth? Can self-effort narrow the income gap between urban and rural youth? This paper attempts to bring intergenerational income transmission and self-effort into the research framework of urban-rural youth income gap. This will provide policy reference for promoting the integration of urban and rural development and building a fair and just society.

\section{Literature Review}

\subsection{Research on the Income Gap between Urban and Rural Workers}

The research on the income gap between urban and rural workers is mainly 
manifested in two aspects. On the one hand, it is the evolution trend of the income gap between the two. For example, Zhu and Ma (2009) found that the proportion of migrant workers' wage income in the monthly income of urban workers decreased year by year from 2002 to 2007. After that, Li Peilin et al. (2010) compared and analyzed the data of two "Chinese Social Survey" in 2006 and 2008, and found that the monthly income growth rate of migrant workers is significantly faster than that of urban workers, which may indicate that the gap between the two is narrowing. Another research focused on the causes of the income gap between city and rural workers, mainly reflected in the following three points: the first point is to explore the causes of the income gap between city and countryside from the registered residence system, the urban biased economic policies, and the urbanization and industrialization by using the classical two sector theory (Cai \& Yang, 2000; Lu \& Chen, 2004). The second point is to explain the urban-rural income gap by using the difference theory of urban and rural factors (such as financial development, labor productivity, etc.) along the neoclassical economic theory (Hou \& Xu, 2004; Yao, 2005). The third point is to decompose the income gap between urban workers and migrant workers at the micro level through survey data. Many scholars, such as Meng \& Zhang (2001), Yao \& Lai (2004), Xing (2008) and Zhang et al. (2014), believe that the income difference between migrant workers and urban workers is mainly caused by the differences in labor characteristics, among which education is the most important reason. Cheng and Bian (2014) emphasized that social capital difference is the micro mechanism to maintain and solidify the income gap between migrant workers and urban workers. However, Lai Desheng (1996), Cai (2001) and Liu Jingming (2006) pointed out that labor market segmentation may have an impact on the income gap between urban and rural workers. Further research by Tian (2010) confirms the above viewpoint. In addition, some scholars, such as Wang Meiyan (2005), Xie and Yao (2006), Deng Quheng (2007), etc., used different survey data to find that market discrimination can explain about $50 \%$ of the income gap between urban and rural workers.

\subsection{Research on Intergenerational Income Transmission}

It can be said that the external factors such as market segmentation are the external objective reasons for the excessive income gap between urban and rural workers, while the "poor" human capital and social capital are the main internal factors for the low income of migrant workers or rural workers. From the perspective of Intergeneration, these internal factors can be transmitted from father to son through family field. For example, Roemer (1998) thinks that parents can influence their children by investing in human capital and helping them establish social relations, which are closely related to their economic income. A large number of literatures have confirmed that there is a strong intergenerational income correlation in western developed countries (Solon, 1992; Zimmerman, 1992; 
Mazumder, 2001). The intergenerational income elasticity of urban residents in China from 1995 to 1988 is 0.384 and 0.420 respectively (Wang Haigang, 2005). Based on CHNS data, Yao and Zhao (2006) concluded that the intergenerational income elasticity of China is about 0.7 , which is much higher than that of European and American countries.

How to interpret the family story of intergenerational transmission? Scholars try to explore the transmission mechanism of intergenerational income. Becker and Tomes (1986) established an economic model earlier to theoretically explain the role of human capital in the process of intergenerational income transmission. Sociologists mainly discuss the intergenerational income flow mechanism from the perspective of family cultural capital. With the increase of available data, Bjorklund et al. (2005) and other scholars compared the intergenerational income elasticity of "biological father offspring" and "non biological father offspring" samples, so as to explain the influence of genetic talent on intergenerational income transmission. Research by scholars Chen Lin and Yuan Zhigang (2012) shows that human capital, social capital and wealth capital account for more than $60 \%$ of intergenerational income transmission. Yang and Deng (2016) believe that direct transmission, human capital transfer and job choice transfer are the three main paths.

If intergenerational transmission can widen the income gap, can the children's efforts change destiny? For the children whose parents belong to the low-income class, they must make greater efforts to reach a certain income level (De Figueiredo \& Ziegelmann, 2010). With the increase of income inequality, "environmental variables" such as family background may play an increasingly important role (Bourguignon et al., 2007; Álvarez \& Menéndez, 2016). Shi et al. (2018) used the data of CGSS in 2013 and found that environmental factors (including father's occupation and other variables) and effort factors (including their own education and other variables) contributed $75.6 \%$ and $24.4 \%$ to China's income inequality in the context of Roemer theory.

In a word, wage difference literature mainly uses mean decomposition and distribution decomposition (Guo et al., 2011). Research on the income gap between urban and rural workers mostly uses some specific decomposition methods, such as Neumark, brown and MM2005 (Meng \& Deng, 2014). However, the literature only focuses on the characteristic variables of urban and rural workers, and does not consider the income of parents in family background. The above literature suggests that there may be a high intergenerational income correlation in China. Based on a large number of literature and real data, Xue and $\mathrm{He}$ (2017) pointed out the possibility of intergenerational transmission to expand the urban-rural income gap,, but did not conduct in-depth quantitative empirical research. Furthermore, can the children's efforts alleviate the income gap between urban and rural areas? There are few literatures about it. Therefore, based on the data of China Health and Nutrition Survey (CHNS) from 1991 to 2015, this paper mainly uses the RIF unconditional quantile regression and de- 
composition method to study the following issues: first, which is the more important impact of parents' income and their own efforts on the income of urban and rural youth? Second, how much influence do parents' income and their own efforts have on the income gap between urban and rural youth? Third, what is the intergenerational transmission path of parents' income? In the past studies, the characteristic variables such as workers' education level and work industry were regarded as the factors influencing the income difference between urban and rural workers. This paper believes that these factors are closely related to the income of their parents, so they are included in the intergenerational transmission scenario. In addition, most of the relevant literatures regard education level as an individual effort variable. In this paper, we consider that there may be a high correlation between individual education and paternal education, parents' income and other variables, so we use the working hours per week as the effort variable (Niehues \& Peichl, 2011).

\section{Research Design}

\subsection{Data Sources}

This paper mainly uses the data from China Health and Nutrition Survey (CHNS). Considering the characteristics of China's urban and rural economic development, the CHNS survey randomly selected about 4400 households in 9 provinces (Liaoning, Jiangsu, Shandong, Henan, Hubei, Hunan, Guangxi Zhuang Autonomous Region, Guizhou and Heilongjiang) in the eastern, Western and central China. On the basis of establishing data indicators in the aspects of residents' health and socio-economic development, the longitudinal data in 1989, 1991, 1993, 1997, 2000, 2004, 2006, 2009, 2011 and 2015 were formed. According to the age classification standard of the World Health Organization in 2013, the sample under 44 is defined as youth. At the same time, considering the independent decision-making ability and labor participation, the lower age limit is 18 years old. The definition of "urban and rural" is based on the registered residence type in CHNS. Due to the lack of weekly working hours of the respondents in 1989, a total of 9 rounds of survey data from 1991 to 2015 were selected. In order to increase comparability, income data processed by CPI index over the years are selected. The relevant information of urban and rural youth and head of household was screened out, and then the urban and rural youth and their parents were accurately matched according to the family member relationship. In order to minimize the error of life cycle when a family appears repeatedly in 25 years, we choose the survey year data of young children who are closest to 35 years old. A total of 4675 samples were obtained by deleting various missing values and abnormal values, including 1888 urban samples and 2787 rural samples.

\subsection{Variable Description}

- Income variables. The individual income of urban residents in CHNS in- 
cludes wage income, bonus and subsidy income and other kinds of subsidy income; besides the above part, the individual income of rural residents also includes the income of family agriculture and fishery, handicraft industry and business operation. The sum of each sub item income is taken as the annual income variable of parents and young people, and the logarithmic treatment is made. In fact, for the rural youth, most of them are engaged in non-agricultural work all the year round, and their income is basically equal to the non-agricultural wage income.

- Education years of youth. The highest education level was reported in the CHNS adult questionnaire. Code 1 stands for primary school, code 2 for junior high school, code 3 for high school, code 4 for secondary vocational school, code 5 for junior college or university, code 6 for master's degree or above. According to the above information, the education level of urban and rural youth is converted into the number of years of education, that is, the actual number of years of formal school education.

- Weekly working hours of youth. China's "labor law" stipulates that the standard working hours per week is 40 hours. If the number of working hours per week exceeds 40 hours, we consider that there is overtime. The longer the overtime, the harder you work. Therefore, this paper uses this variable to express the work effort of urban and rural youth. In the CHNS adult questionnaire, the information about how many hours the respondents worked in the last week was given. Here, the number of working hours per week is logarithmic.

- Youth BMI index. BMI is one of the important indicators reflecting the health status of the body. The specific calculation method is the ratio of weight $(\mathrm{kg})$ to height $(\mathrm{m})$ square. The survey data show that the BMI of urban and rural youth is in the normal range of 18.5 - 23.9, but relatively speaking, urban youth is "fatter" than rural youth.

- Youth occupation level. CHNS adult questionnaire reported the main occupation of the interviewees. For example, senior professional and technical workers, general professional and technical workers, technical workers, service industry personnel and other 12 categories. According to the occupational classification table of Erikson and Goldthorpe (2002), transformed individual occupation into grade variable for empirical analysis.

- To reflect the income distribution characteristics of urban and rural youth and their parents. In this paper, the kernel density estimation is used for simulation, as shown in Figure 1 and Figure 2. Figure 1 shows that the income distribution of urban and rural youth shows multi peak characteristics, which indicates that the level of inequality between urban and rural youth is relatively high, but the income concentration of urban youth is slightly higher than that of rural youth. The distribution curve of urban youth is obviously on the right side of rural youth, indicating that the average income of urban youth is higher than that of rural youth. Figure 2 depicts the kernel density 


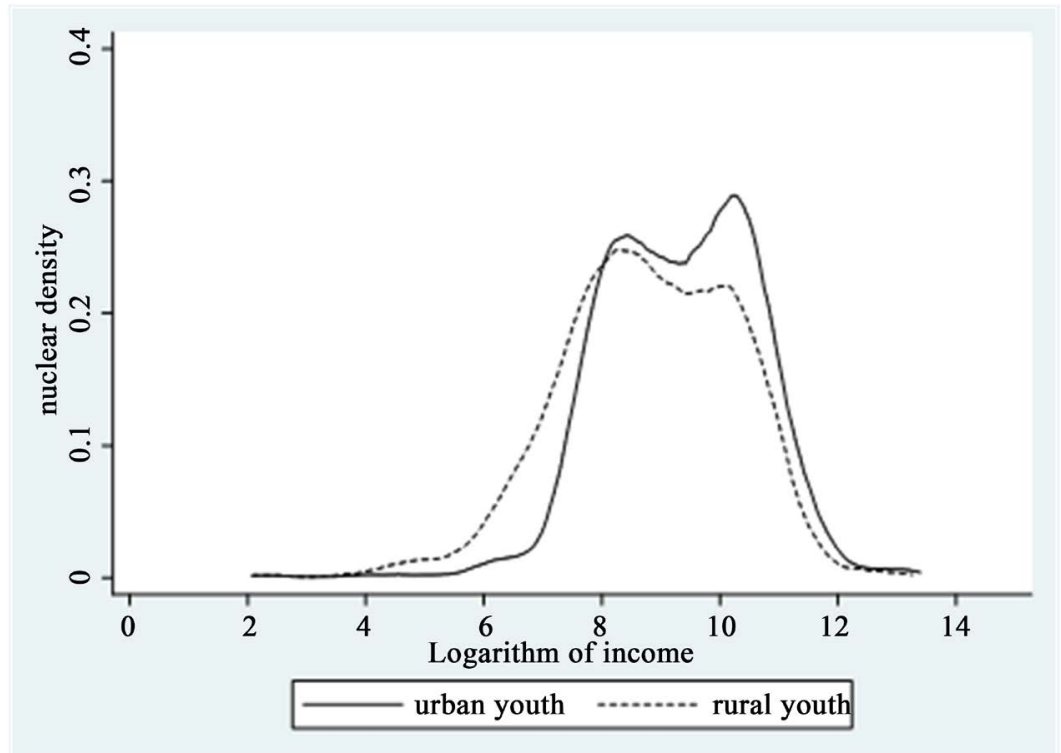

Figure 1. Income distribution of urban and rural youth.

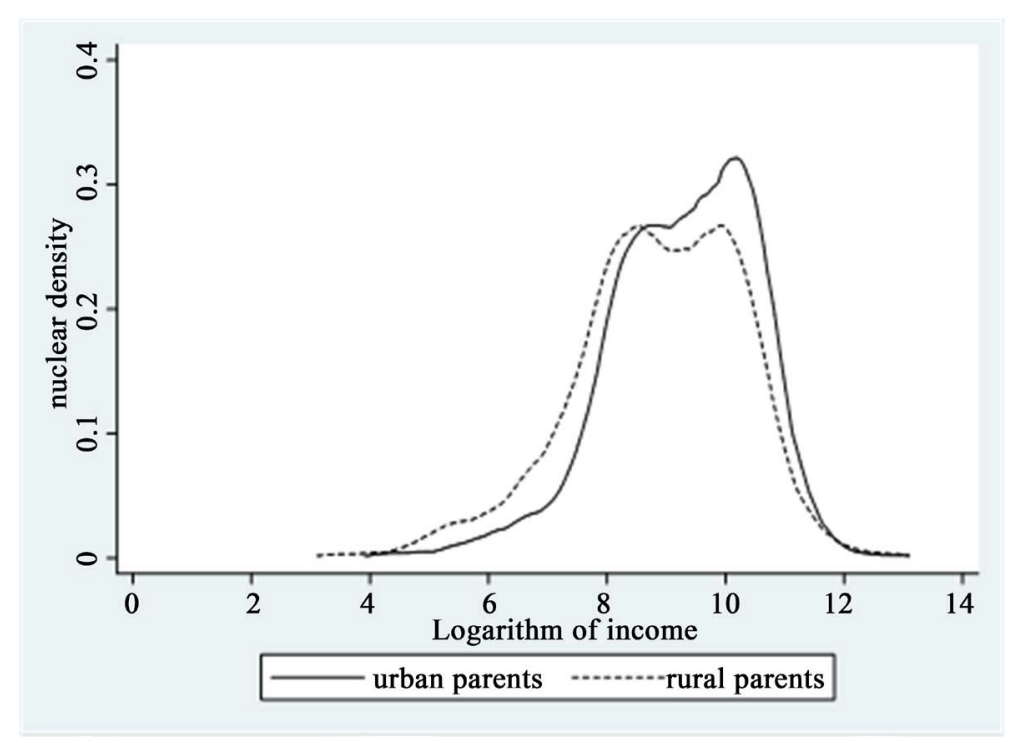

Figure 2. Income distribution of parents in urban and rural areas.

distribution of the urban parents' income. The income of rural parents has obvious left-hand tail, which shows that there are relatively more low-income people in rural parents. Other aspects are similar to the income distribution of urban and rural youth.

In this paper, the number of working hours per week is taken as the variable of whether urban and rural youth work hard. Figure 3 shows the working hours of urban and rural youth at each quantile. It can be seen from Figure 3 that under the $25^{\text {th }}$ percentile, the working hours of rural youth are slightly less than that of urban youth. However, after the 25th percentile, the working hour's gap between urban and rural youth gradually widened. The difference increased from 4 hours at 50 to 9 hours at 90 and to 19 hours at 99 . 


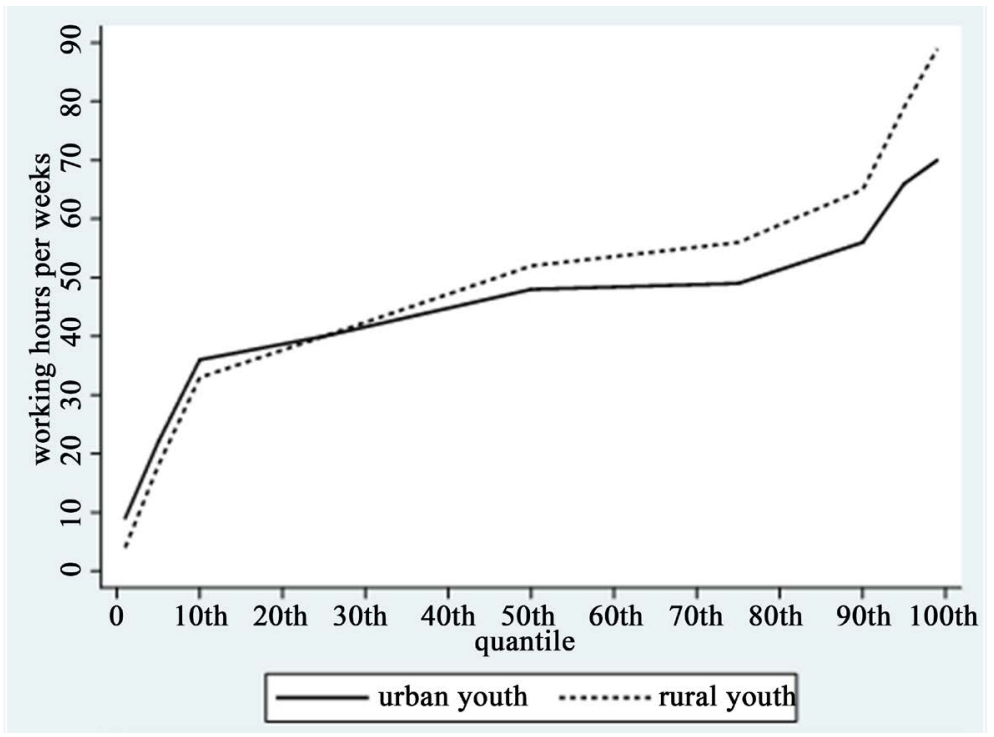

Figure 3. Quantile distribution of working hours of urban and Rural Youth Week.

Table 1. Descriptive statistical comparison of other variables between urban and rural youth.

\begin{tabular}{ccccc}
\hline variable & mean value & Standard error & minimum value & Maximum value \\
\hline Years of Education & $12.436(8.858)$ & $3.358(4.321)$ & $9(5)$ & $19(19)$ \\
Occupation grade & $6.19(4.328)$ & $2.983(3.080)$ & $1(1)$ & $12(12)$ \\
BMI index & $22.832(22.510)$ & $3.558(3.646)$ & $15.564(14.458)$ & $37.197(42.969)$ \\
Age & $27.290(33.708)$ & $4.099(11.428)$ & $18(18)$ & $35(44)$ \\
\hline
\end{tabular}

Note: the values in brackets are the corresponding variables of rural youth, and the values before brackets are the corresponding variables of urban youth.

In addition, Table 1 also gives descriptive statistical indicators of other variables of urban and rural youth. It can be seen that the urban youth are better than the rural youth in terms of education years, occupation grade and BMI index, but the rural youth is older than the urban youth in the sample.

\subsection{Model Building}

According to Roemer (1998) and Bourguignon et al. (2007), hypothesized that the external environmental variables and responsible effort variables are the determinants of urban and rural youth income. The income equation is set as follows: $y_{t}=f\left(\right.$ income $_{t}^{p}$, work $t_{t}$, age ${ }_{t}$, age $\left._{t}^{2}, \varepsilon_{t}\right)$ among $t=1$ Urban youth, $t=0$ Rural youth. $y_{t}$ Represents the logarithm of youth income, Environmental variables are logarithm of parents' income income $t_{t}^{p}$ express, The effort variable is measured in hours per week work $t_{t}$, The control variable was age age $e_{t}$ and age squared term age $e_{t}^{2}, \varepsilon_{t}$ Represents a random error term. For the convenience of discussion, all the above independent variables and control variables are uniformly expressed as $X$. This paper uses the unconditional quantile regression model based on the Recentered Influence Function (RIF) proposed by Firpo et 
al. (2009). On this basis, combined with the Oaxaca-Blinder mean decomposition method, we can get the contribution rate of single variable to the income difference, characteristic effect or coefficient effect in each quantile. The specific process is as follows:

The first step is to construct the income counterfactual distribution and decompose the income gap between urban and rural youth into characteristic effect and coefficient effect. According to Firpo et al. (2007), the following three weight functions are constructed under the conditions of neglectability and overlapping support:

$$
W_{1}(t)=\frac{t}{p}, W_{0}(t)=\frac{1-t}{1-p}, W_{c}(t, X)=\frac{1-t}{p} \cdot \frac{p(X)}{1-p(X)}, \text { among } p \text { Represents }
$$

the proportion of urban youth, $p(X)$ Denotes a given $X$ Under the condition of The individual tendency to become urban youth scored. It can be obtained by merging two samples and running logit model. According to the ideas of Firpo et al. (2007), the difference of urban and rural youth income in $\tau$ quantile can be divided into characteristic effect and coefficient effect:

$$
Q_{\tau}\left(y_{1}\right)-Q_{\tau}\left(y_{0}\right)=\left[Q_{\tau}\left(y_{1}\right)-Q_{\tau}\left(y_{c}\right)\right]+\left[Q_{\tau}\left(y_{c}\right)-Q_{\tau}\left(y_{0}\right)\right]
$$

$Q_{\tau}\left(y_{c}\right)$ Representing counterfactual income $\tau$ Quantile. On the right side of the equation, the first part shows the income difference (characteristic effect) caused by the difference of urban and rural youth characteristics, and the second part measures the income difference (coefficient effect) or "discrimination effect" caused by the difference of characteristic return rate of urban and rural youth.

The second step is to decompose the overall difference into variables by using the Recentered Influence Function (RIF) regression model. First, Solving quantile concentration influence function of dependent variable $y$.

$$
R I F\left(y_{i} ; Q_{\tau}^{i}, F_{y_{i}}\right)=Q_{\tau}+\frac{\tau-I\left(y_{i} \leq Q_{\tau}^{i}\right)}{f_{y_{i}\left(Q_{\tau}^{I}\right)}} \quad i=1,0, c
$$

$I($.$) is Indicates the function, f_{y_{i}}($.$) representing density function of mar-$ ginal distribution of $y_{i}$. Under the assumption of linear parameters, the RIF variable was used for OLS regression to explanatory variable $\mathrm{x}$. After the RIF's regression coefficient is obtained, if the rural youth is taken as the benchmark group, the overall characteristic effect and coefficient effect of urban and rural youth can be further decomposed into $k$ single variables:

$$
\begin{gathered}
\left(\bar{X}_{1}-\bar{X}_{0}\right) \hat{\beta}_{0}^{\tau}=\sum_{k=1}^{K}\left(\bar{X}_{1 k}-\bar{X}_{0 k}\right) \hat{\beta}_{0 k}^{\tau} \\
\bar{X}_{1}\left(\hat{\beta}_{1}^{\tau}-\hat{\beta}_{0}^{\tau}\right)=\sum_{k=1}^{K} \bar{X}_{1 k}\left(\hat{\beta}_{1 k}^{\tau}-\hat{\beta}_{0 k}^{\tau}\right)
\end{gathered}
$$

\section{Empirical Research Results}

According to the above formula, RIF's quantile regression is carried out on the 
income determination equation of urban and rural youth. The specific results are shown in Table 2 and Table 3. On this basis, FFL method is used to decompose. The results are shown in Table 4 . The results of RIF quantile regression in Table 2 and Table 3 show that the influence of working hours per week on the income of rural youth is different at different points. The regression coefficients at 10 and 25 quantiles were 0.443 and 0.245 respectively, which were significant at 0.01 and 0.05 levels. However, after the $50^{\text {th }}$ percentile, the impact of working

Table 2. RIF's regression results of rural youth income under each quantile.

\begin{tabular}{|c|c|c|c|c|c|}
\hline variable & $10^{\text {th }}$ & $25^{\text {th }}$ & $50^{\text {th }}$ & $75^{\text {th }}$ & $90^{\text {th }}$ \\
\hline \multirow{2}{*}{$\begin{array}{c}\text { Logarithm of working hours per } \\
\text { week }\end{array}$} & $0.443^{\star * *}$ & $0.245^{\star *}$ & $0.220^{*}$ & $0.079^{*}$ & 0.006 \\
\hline & $(0.122)$ & $(0.129)$ & $(0.142)$ & $(0.094)$ & $(0.111)$ \\
\hline \multirow[t]{2}{*}{ Logarithm of parents' income } & $0.674^{* * *}$ & $0.704^{* * *}$ & $0.621^{\star * *}$ & $0.438^{* * *}$ & $0.397^{\star * *}$ \\
\hline & $(0.049)$ & $(0.045)$ & $(0.054)$ & $(0.048)$ & $(0.065)$ \\
\hline \multirow[t]{2}{*}{ Age } & $0.063^{\star *}$ & $0.093^{\star}$ & $0.117^{\star *}$ & $0.157^{* * *}$ & -0.019 \\
\hline & $(0.078)$ & $(0.049)$ & $(0.070)$ & $(0.054)$ & $(0.082)$ \\
\hline \multirow[t]{2}{*}{ Age squared } & $-0.0007^{\star *}$ & $-0.001^{\star}$ & $-0.001^{* *}$ & $-0.002^{* *}$ & 0.001 \\
\hline & $(0.001)$ & $(0.0001)$ & $(0.001)$ & $(0.001)$ & $(0.002)$ \\
\hline \multirow[t]{2}{*}{ constant } & $0.747^{\star *}$ & $0.433^{*}$ & $0.569^{* *}$ & $2.913^{* * *}$ & $6.387^{\star * *}$ \\
\hline & $(1.228)$ & $(1.011)$ & $(1.079)$ & $(0.807)$ & $(1.430)$ \\
\hline \multirow{2}{*}{ Model checking } & $\mathrm{F}=23.12$ & $\mathrm{~F}=45.39$ & $\mathrm{~F}=78.35$ & $\mathrm{~F}=53.16$ & $\mathrm{~F}=40.55$ \\
\hline & $\mathrm{R}^{2}=0.038$ & $\mathrm{R}^{2}=0.268$ & $\mathrm{R}^{2}=0.375$ & $\mathrm{R}^{2}=0.291$ & $\mathrm{R}^{2}=0.198$ \\
\hline
\end{tabular}

Note: ${ }^{* *}, * *, *$ are significant at $0.01,0.05$ and 0.1 levels respectively; the robust standard error is shown in brackets.

Table 3. RIF's regression results of urban youth income under each quantile.

\begin{tabular}{|c|c|c|c|c|c|}
\hline variable & $10^{\text {th }}$ & $25^{\text {th }}$ & $50^{\text {th }}$ & $75^{\text {th }}$ & $90^{\text {th }}$ \\
\hline \multirow{2}{*}{$\begin{array}{c}\text { Logarithm of working hours } \\
\text { per week }\end{array}$} & $0.0465^{\star *}$ & $0.0810^{* *}$ & $0.0383^{*}$ & $0.0337^{\star}$ & 0.00964 \\
\hline & $(0.0810)$ & $(0.189)$ & $(0.189)$ & $(0.187)$ & $(0.161)$ \\
\hline \multirow[t]{2}{*}{ Logarithm of parents' income } & $0.810^{* * *}$ & $0.874^{* * *}$ & $0.860^{* * *}$ & $0.754^{\star * *}$ & $0.491^{* * *}$ \\
\hline & $(0.0604)$ & $(0.0418)$ & $(0.0402)$ & $(0.0621)$ & $(0.0738)$ \\
\hline \multirow[t]{2}{*}{ Age } & $0.229^{* *}$ & $0.153^{*}$ & $0.201^{\star * *}$ & $0.195^{\star *}$ & 0.144 \\
\hline & $(0.199)$ & $(0.130)$ & $(0.154)$ & $(0.136)$ & $(0.193)$ \\
\hline \multirow[t]{2}{*}{ Age squared } & $-0.00297^{\star *}$ & $-0.00175^{\star *}$ & $-0.00282^{*}$ & $-0.00247^{\star *}$ & -0.00146 \\
\hline & $(0.00360)$ & $(0.00234)$ & $(0.00273)$ & $(0.00242)$ & $(0.00342)$ \\
\hline \multirow[t]{2}{*}{ constant } & $2.933^{\star *}$ & $2.412^{\star}$ & $2.190^{\star *}$ & $0.506^{* * *}$ & 2.724 \\
\hline & $(2.834)$ & (1.939) & $(2.102)$ & $(1.845)$ & $(2.870)$ \\
\hline \multirow{2}{*}{ Model checking } & $\mathrm{F}=22.31$ & $\mathrm{~F}=47.02$ & $\mathrm{~F}=79.57$ & $\mathrm{~F}=55.29$ & $\mathrm{~F}=42.32$ \\
\hline & $\mathrm{R}^{2}=0.036$ & $\mathrm{R}^{2}=0.273$ & $\mathrm{R}^{2}=0.394$ & $\mathrm{R}^{2}=0.306$ & $\mathrm{R}^{2}=0.207$ \\
\hline
\end{tabular}

Note: ${ }^{* *},{ }^{* *},{ }^{*}$ are significant at $0.01,0.05$ and 0.1 levels respectively; the robust standard error is shown in brackets. 
hours per week on the income of rural youth gradually decreased, and the significance was low. For urban youth, the impact of working hours at each quantile (except for the 90 quantile) was less than that of rural youth. For example, in the $10^{\text {th }}$ and $25^{\text {th }}$ percentile, the regression coefficient of working hours of urban youth is only 0.0465 and 0.0810 . Similarly, the regression coefficient of weekly working hours of urban youth above 50 quantiles is positive, but the significance gradually decreases. This means that only increasing working time or self-effort at the low-end quantile level can promote the income of urban and rural youth, and the effort effect of rural youth is significantly greater than that of urban youth. Because of the double logarithm model, the income regression coefficient of urban and rural youth is intergenerational income elasticity. The results show that the parents' income has a highly significant effect on the income of urban and rural youth in each quantile. At the same time, the intergenerational elasticity of rural sample is larger than that of rural sample. For example, the intergenerational income elasticity of urban youth is 0.810 , while that of rural youth is 0.674 in $10^{\text {th }}$ quantile. This means that the income of parents has a significant impact on the income of urban and rural youth, and the influence of urban parents on their offspring is greater. However, the intergenerational income elasticity of urban and rural youth shows an inverted $U$ trend, which is similar to the research results of Wei and Zhang (2009). This also means that at the quantile of "middle part", the income of parents has a greater impact on the income of urban and rural youth. In addition, the regression coefficient of urban and rural youth's age is positive in most quantiles, while the square regression coefficient of age is negative, that is, the relationship between age and income presents an inverse $\mathrm{U}$, which is consistent with the conclusion of most literature studies.

The results of RIF's decomposition in Table 4 show that with the increase of quantile level, the income gap between urban and rural youth shows a trend of first decreasing and then increasing. There is a large income gap between urban and rural youth at both ends of the quantile, while the gap in the middle part is small. On the whole, the characteristic effect (interpretable part) is the main cause of the income gap between urban and rural youth, but its contribution rate at each quantile shows a trend of first increasing and then decreasing. However, the coefficient effect (unexplained part) shows an opposite trend.

In the explainable part, there is a significant positive effect of father's income on the income difference between urban and rural youth at 0.01 level. It shows that the income of parents is the driving force to widen the income gap between urban and rural youth. However, there are significant differences in different quantiles. In the $10^{\text {th }}$ and $25^{\text {th }}$ quantiles, the income of parents can explain $98.6 \%$ and $142.27 \%$ of the income gap between urban and rural youth, respectively. The $50^{\text {th }}$ percentile has the greatest influence, and its explanatory power is as high as $269.9 \%$. With the increase of quantile, the influence of parents' income began to decline. From $139.2 \%$ of $75^{\text {th }}$ percentile to $88.8 \%$ of $90^{\text {th }}$ quantile. The influence of working hours per week on each quantile was low or positive or negative. But 
Table 4. RIF's decomposition results of income gap between urban and rural youth.

\begin{tabular}{|c|c|c|c|c|c|}
\hline & $10^{\text {th }}$ & $25^{\text {th }}$ & $50^{\text {th }}$ & $75^{\text {th }}$ & $90^{\text {th }}$ \\
\hline Total difference & $0.282^{* * *}$ & $0.220^{* * *}$ & $0.186^{* * *}$ & $0.199^{* * *}$ & $0.242^{* * *}$ \\
\hline Characteristic effect & $0.319^{* *}$ & $0.354^{\star * *}$ & $0.561^{\star *}$ & $0.296^{\star \star *}$ & $0.228^{\star * *}$ \\
\hline Interpretable part (\%) & $113 \%$ & $161.10 \%$ & $301.90 \%$ & $148.70 \%$ & $94 \%$ \\
\hline Logarithm of working hours per week & $0.001^{\star}$ & $-0.011^{*}$ & $-0.012^{\star *}$ & $-0.009^{\star *}$ & $-0.005^{\star *}$ \\
\hline Logarithm of parents' income & $0.278^{\star * *}$ & $0.313^{\star * *}$ & $0.502^{* * *}$ & $0.277^{\star * *}$ & $0.215^{\star * *}$ \\
\hline Age & 0.093 & 0.113 & $0.205^{\star}$ & $0.085^{\star}$ & $0.044^{*}$ \\
\hline Age squared & -0.053 & -0.06 & $-0.134^{\star}$ & $-0.057^{\star *}$ & $-0.026^{* * *}$ \\
\hline Coefficient effect & $-0.038^{* *}$ & $-0.134^{* * *}$ & $-0.375^{\star *}$ & $-0.097^{\star * *}$ & $0.014^{* *}$ \\
\hline Unexplainable part & $-13 \%$ & $-61.10 \%$ & $-201.90 \%$ & $-48.70 \%$ & $6 \%$ \\
\hline Logarithm of working hours per week & $-2.249^{* *}$ & $-1.622^{\star *}$ & $-1.461^{\star *}$ & $0.218^{* *}$ & $0.066^{* *}$ \\
\hline Logarithm of working hours per week & $0.285^{\star * *}$ & $1.420^{\star * *}$ & $2.682^{* * *}$ & $1.224^{* * *}$ & $1.562^{* * *}$ \\
\hline Age & $-3.144^{* *}$ & $-2.219^{* * *}$ & $-0.057^{\star *}$ & $-1.36^{\star *}$ & $-2.271^{\star *}$ \\
\hline Age squared & $1.567^{\star}$ & 1.127 & $-0.127^{*}$ & $0.479^{* *}$ & 0.925 \\
\hline constant & $3.503^{\star * *}$ & $1.160^{\star \star \star *}$ & $-1.413^{\star * *}$ & $-0.658^{\star \star * *}$ & $-0.268^{\star \star *}$ \\
\hline
\end{tabular}

Note: ${ }^{* *},{ }^{* *},{ }^{*}$ are significant at $0.01,0.05$ and 0.1 levels, respectively.

because the variables used in the model are logarithm of weekly working hours and logarithm of annual income, it still has some practical and theoretical significance. In the 10 quantiles, the coefficient of weekly working hours is positive, while the coefficients of other quantiles are negative. This shows that except for the low quantile, this variable has a negative impact on the income gap between urban and rural youth, or it can narrow the income gap between urban and rural youth under certain other conditions. In fact, in the low-level labor market, there are a large number of rural youth who live on temporary or part-time jobs, often in the "unemployment status". Compared with most of the urban youth who are engaged in formal occupation, the rural youth have no advantage in working time, thus widening the income gap. But in the other quantiles, the rural youth mainly suppressed the income gap by increasing working time.

In the unexplained part, the coefficient effect is only positive in the 90 quantile, while the coefficient effect in other quantiles is negative. This means that the comprehensive coefficient effect of working hours per week, parents' income and age can narrow the income gap between urban and rural youth to a certain extent. Further analysis found that the working hours of rural youth in the 10, 25 and 50 percentile showed certain advantages. The reason may be that in the middle and low quantile, the rural youth are basically engaged in the "dirty work" that the urban youth are unwilling to do, so they have a higher rate of return advantage. This may be a kind of "reverse discrimination" in the labor market (Zhou \& Su, 2018). with the increase of quantile, the rate of return on working hours of rural youth gradually disappeared, and employment discrimi- 
nation began to appear. The coefficient effect of father's income is highly significant at each quantile, which means that the intergenerational income elasticity coefficient of urban youth has advantages, and the economic income relationship between urban parents and their children is closer. In addition, age can narrow the income gap between urban and rural youth. In fact, compared with the urban youth, the rural youth have lower education years, so they participate in the labor market earlier and gain more work experience. This is the advantage of rural youth's own endowment, so it can narrow the income gap between them to a certain extent. Generally speaking, although the rural youth have disadvantages in the rate of return on their parents' income (intergenerational income elasticity coefficient), the "resultant force" advantage in terms of age and working hours per week exceeds the former, so on the whole (except for the $90^{\text {th }}$ percentile) can stabilize the income gap between urban and rural youth.

\section{Expanding Research: A Comparative Study on the Intergenerational Income Transmission Path of Urban and Rural Youth}

The above part shows that parents' income and intergenerational transmission are the important factors affecting the income gap between urban and rural youth. So what path does intergenerational transmission follow? Is there any difference between urban and rural youth? Considering the availability of data, it is planned to analyze youth human capital (education years), health capital (BMI index) and social capital (occupation level). This paper uses Blanden et al. (2007) for reference to carry out the following research. Firstly, the intergenerational income elasticity of urban and rural youth is obtained. Secondly, the income of urban and rural parents is used to regress the intermediate variables (such as youth occupation level), and then the intermediate variable (such as youth occupation grade) is used for regression analysis of urban and rural youth income. The regression coefficient in the second step can be expressed as the investment tendency of the parents, and the regression coefficient in the third step can be expressed as the influence degree (or rate of return) of the intermediate variable (such as youth occupation grade) on the income of the young children. The paper uses the information of 1888 urban samples and 2787 rural samples from 9 rounds of survey data from 1991 to 2015 to decompose the intergenerational income elasticity of urban and rural youth obtained by mean regression. The specific results are as follows, as shown in Table 5.

The educational years of urban youth account for $25.269 \%$ of the intergenerational income elasticity. The investment coefficient of education is 1.181 , and the corresponding return coefficient is 0.115 . The contribution rate of education years of rural youth is only $15.789 \%$, which is far lower than that of urban families, and the education investment rate (0.993) and return rate (0.077) of rural youth are lower than that of urban youth. This shows that urban families pay more attention to their children's education, and urban youth have higher 
Table 5. Comparison of intergenerational income transmission path between urban and rural youth.

\begin{tabular}{cccc}
\hline Delivery path & coefficient & Urban youth & rural youth \\
\hline \multirow{2}{*}{ BMI index } & Investment propensity & 0.984 & 0.781 \\
& Rate of return & 0.097 & 0.118 \\
& Contribution rate & $17.833 \%$ & $19.043 \%$ \\
\hline \multirow{2}{*}{ Occupation grade } & Investment propensity & 0.859 & 0.602 \\
& Rate of return & 0.125 & 0.237 \\
\hline \multirow{2}{*}{ Years of Education } & Contribution rate & $20.112 \%$ & $29.299 \%$ \\
& Investment propensity & 1.181 & 0.993 \\
& Rate of return & 0.115 & 0.077 \\
& Contribution rate & $25.269 \%$ & $15.789 \%$ \\
\hline \multirow{2}{*}{ Unobservable variable } & Investment propensity & 0.840 & 0.760 \\
& Rate of return & 0.234 & 0.229 \\
\hline
\end{tabular}

Note: intergenerational income elasticity of urban youth is 0.535 , and that of rural youth is 0.485 .

education returns in the labor market. The contribution rate of BMI index to intergenerational income elasticity of rural youth is $19.043 \%$, and has a high rate of return. This may have something to do with physical labor. Rural youth show a higher rate of return in the intergenerational career transfer path, so they account for about $30 \%$ of the intergenerational income elasticity, which is much higher than that of urban youth. It is worth noting that no matter urban youth or rural youth, the contribution rate of family culture and natural endowment heredity is close to $40 \%$, which has a great impact on intergenerational income elasticity.

\section{Conclusion and Enlightenment}

Based on nine rounds of data from China Health and Nutrition Survey (CHNS) from 1991 to 2015, the effects of intergenerational income transmission and self-effort on the income gap between urban and rural youth under different quantiles were studied by using RIF's unconditional quantile regression and decomposition method. The conclusions are as follows:

First, parents' income has a significant impact on the income of urban and rural youth. From different quantiles, whether urban youth or rural youth, parents' income has a significant impact on their income, and the intergenerational income elasticity of urban youth is higher than that of rural youth in each quantile. At the same time, the intergenerational income elasticity of urban and rural youth shows an inverted $U$ trend with the increase of quantile. This conclusion means that the father's income has a greater impact on the income of urban youth, and it is mainly reflected in the median.

Second, hard work only has a significant impact on the income of urban and 
rural youth in the middle and low quantile, and the effect of rural youth is significantly greater than that of urban youth. This conclusion shows that the attempt to increase the income by extending the working hours can only be achieved in the middle and low quantiles, and the high income may be related to other factors.

Thirdly, the characteristic effect is the main factor affecting the income gap between urban and rural youth, especially the income of parents. Although in most quantiles, the weekly working hours of rural youth have certain advantages, which can stabilize the income gap; but due to the "gap between the rich and the poor", the positive characteristic effect of parents' income is far greater than the negative effect of weekly working hours. Therefore, the comprehensive characteristic effect has become the driving force to widen the income gap between urban and rural youth.

Fourth, the coefficient effect can stabilize the income gap between urban and rural youth in multiple quantiles. In the middle and low quantile, the return rate of rural youth's weekly working hours has certain advantages, which indicates that there is "reverse discrimination" against rural youth in the low level labor market; with the increase of quantile, the advantage of rural youth's weekly working hours returns gradually disappears, which shows certain employment discrimination. The age return rate of rural youth has a comparative advantage in each quantile. Although the coefficient effect of parents' income is positive, but this variable has comprehensive negative effect with age and working hours per week, which can stabilize the income gap to a certain extent.

In order to further explore the intergenerational transmission mechanism, this paper decomposes the intergenerational income elasticity obtained by mean regression, and finds that the intergenerational income of urban families is mainly transmitted through education, while the intergenerational income transmission of rural families is more reflected in the youth career path. In addition, nearly $40 \%$ of intergenerational income elasticity of urban and rural youth can be explained by unobservable variables.

In view of the above conclusions, this paper gets the following enlightenment: first, pay attention to the role of tax regulation. From the perspective of fairness and justice, we should further explore and timely levy inheritance and gift tax, and strengthen the regulatory function of national tax on income distribution. Second, further play the regulatory role of the "labor contract law" to ensure that the principles of equal pay for equal work and distribution according to work are implemented in place. Third, increase the investment of public education resources in rural areas to make up for the lack of investment in education for children of rural families.

Finally, it is worth noting that this paper does not consider the impact of urbanization on the income gap between urban and rural youth, and does not consider the spatial evolution of the income gap between urban and rural youth. In addition, when selecting the youth sample, only the eldest son or eldest daughter 
is reserved for the families with many children, which may have some influences on the estimation results of rural families with "boy preference". This will be further explored in the follow-up study.

\section{Funding}

This research was funded by The National Social Science Fund of China "Research on the formation mechanism and promotion strategy of the sense of gain of the relative poverty population from the perspective of social mobility", grant number 20BSH128.

\section{Conflicts of Interest}

The authors declare no conflicts of interest regarding the publication of this paper.

\section{References}

Álvarez, A. S., \& Menéndez, A. J. L. (2016). Inequality of Opportunity and Income Inequality in Spain: An Analysis over Time, Working Papers 423, ECINEQ, Society for the Study of Economic Inequality. https://ideas.repec.org/p/inq/inqwps/ecineq2016-423.html

Becker, G. S., \& Tomes, N. (1986). Human Capital and the Rise and Fall of Families. Journal of Labour Economics, 4, 1-39. https://doi.org/10.1086/298118

Bjorklund, A., Lindahl, M., \& Plug, E. (2005). The Origins of Intergenerational Associations: Lessons from Swedish Adoption Data. Institute for the Study of Labor (IZA). https://papers.ssrn.com/sol3/papers.cfm?abstract id=807485

Blanden, J., Gregg, P., \& Macmillan, L. (2007). Accounting for Intergenerational Income Persistence: Noncognitive Skills, Ability and Education. The Economic Journal, 117, 43-60. https://doi.org/10.1111/j.1468-0297.2007.02034.x

Bourguignon, F. J., Ferreira, F. H. G., \& Menéndez, M. (2007). Inequality of Opportunity in Brazil. Review of Income and Wealth, 53, 585-618. https://doi.org/10.1111/j.1475-4991.2007.00247.x

Cai, F. (2001). Two Processes of Labor Migration and Their Institutional Barriers. Sociological Research, 4, 44-51.

Cai, F., \& Yang, T. (2000). Political Economy of Urban-Rural Gap. Chinese Social Sciences, 4, 11-22, 204.

Chen, L., \& Yuan, Z. G. (2012). The Trend and Internal Transmission Mechanism of Intergenerational Income Mobility in China. World Economy, 6, 115-131.

Cheng, C., \& Bian, Y. J. (2014). Reproduction of Social Capital and Inequality: Taking the Income Gap between Migrant Workers and Urban Workers as an Example. Society, 34, 67-90.

De Figueiredo, E. A., \& Ziegelmann, F. A. (2010). Estimation of Opportunity Inequality in Brazil Using Nonparametric Local Logistic Regression. The Journal of Development Studies, 46, 1593-1606. https://doi.org/10.1080/00220388.2010.500661

Deng, Q. H. (2007). Income Difference between Urban Residents and Floating Population: A Decomposition Based on Oaxaca Blinder and Quantile Methods. China Population Science, 2, 8-16.

Erikson, R., \& Goldthorpe, J. H. (2002). Intergenerational Inequality: A Sociological Pers- 
pective. Journal of Economic Perspectives, 16, 31-44.

https://doi.org/10.1257/089533002760278695

Firpo, S., Fortin, N., \& Lemieux, T. (2007). Decomposing Wage Distributions Using Recentered Influence Function Regressions. Mimeo, Department of Economics, University of PUC-RIO.

Firpo, S., Fortin, N. M., \& Lemieux, T. (2009). Unconditional Quantile Regressions. Econometrica, 77, 953-973. https://doi.org/10.3982/ECTA6822

Guo, J. Q., Jiang, L., \& Lu, L. L. (2011). Review on the Decomposition Method of Wage Difference. Economics (Quarterly), 10, 363-414.

Hou, F.Y., \& Xu, H. (2004). Human Capital Explanation of Urban-Rural Development Gap. Journal of Theory, 24, 2-45, 129.

Lai, D. S. (1996). On the Institutional Segmentation of Labor Market. Economic Science, $6,19-23$.

Li, P. L., \& Li. W. (2010). Economic Status and Social Attitudes of Migrant Workers in Recent Years. Chinese Social Sciences, 1, 119-131.

Liu, J. M. (2006). Structural Change of Labor Market and Return of Human Capital. Sociological Research, 6, 89-119.

Lu, M., \& Chen, Z. (2004). Urbanization, Urban Tendency Economic Policy and Urban-Rural Income Gap. Economic Research, 6, 50-58.

Mazumder, B. (2001). Earnings Mobility in the US: A New Look at Intergenerational Inequality. Federal Reserve Bank of Chicago Working Paper NOWP-01-18, 1-38.

Meng, F. Q., \& Deng, B. G. (2014). China's Registered Residence Discrimination in Labor Market and Wage Difference between Urban and Rural Areas Based on Quantile Regression and Decomposition Analysis. China's Rural Economy, 6, 56-65.

Meng, X., \& Zhang, J. (2001). The Two-Tier Labor Market in Urban China: Occupational Segregation and Wage Differentials between Urban Residents and Rural Migrants in Shanghai. Journal of Comparative Economics, 29, 485-504.

https://doi.org/10.1006/jcec.2001.1730

Niehues, J., \& Peichl, A. (2011). Lower and Upper Bounds of Unfair Inequality: Theory and Evidence for Germany and the US. IZA Discussion Papers, 43, 73-99. https://doi.org/10.2139/ssrn.1916583

Roemer, J. E. (1998). Equality of Opportunity. Cambridge, MA: Harvard University Press. https://doi.org/10.4159/9780674042872

Shi, X. J., Wei, L. B., Fang, S. L., \& Gao, X. W. (2018). Inequality of Opportunity in China's Income Distribution. Management World, 34, 27-37.

Solon, G. (1992). Intergenerational Income Mobility in the United States. The American Economic Review, 82, 393-408.

Tian, F. (2010). Study on the Income Gap between Urban Workers and Migrant Workers. Sociological Research, 25, 87-105.

Wang, H. G. (2005). Intergenerational Mobility of Chinese Residents' Income Distribution. Economic Science, 2, 18-25.

Wang, M. Y. (2005). Employment Opportunities and Wage Differences in Urban Labor Market: A Study on Employment and Remuneration of Migrant Workers. Chinese Social Sciences, 5, 36-46.

Wei, Y., \& Zhang, C. Y. (2009). Research on Intergenerational Income Flow and Income Inequality. Journal of Graduate School of Chinese Academy of Social Sciences, 4, 97-102. 
Xie, S. S., \& Yao, X. G. (2006). Econometric Analysis of Wage Discrimination of Migrant Workers. China Rural Economy, 4, 49-55.

Xing, C. B. (2008). Income Gap between Migrant Workers and Urban Workers. Management World, 5, 55-64.

Xue, B. G., \& He, L. C. (2017). Intergenerational Transmission and Correction of Urban-Rural Income Gap in China. Hebei Academic Journal, 2, 135-139.

Yang, X. M., \& Deng, Q. H. (2016). Intergenerational Transmission of Urban Residents' Income and Its Formation Mechanism: An Empirical Analysis Based on 2008 Tianjin Household Survey Data. Finance and Trade Economy, 11, 47-61.

Yao, X. G., \& Lai, P. Q. (2004). Differences between China's Urban and Rural Registered Residence Relations in Labor Relations. Economic Research, 7, 82-90.

Yao, X. G., \& Zhao, L. Q. (2006). Research on Intergenerational Income Flow and Transmission Path in China: 1989-2000. Selected Papers. The 6th Annual Meeting of China Economics, Wuhan, 16-17 December 2006, 1-16.

Yao, Y. J. (2005). Co-integration Analysis and Granger Causality Test of Financial Development, Urbanization and Urban-Rural Income Gap. China Rural Observation, 2, 2-8, 80 .

Zhang, L., Li, S., Darity Jr., W. A., \& Sharpe, R. V. (2014). Registered Residence Discrimination in China's Labor Market. Management World, 11, 35-46.

Zhou, C. F., \& Su, Q. (2018). The Difference and Decomposition of Employment Quality between Migrant Workers and Urban Workers in China: Decomposition Method Based on RIF's Unconditional Quantile Regression. Agricultural Technology Economy, 6, 32-43.

Zhu, C. C., \& Ma, J. Z. (2009). Generalized Spillover of Rural Human Capital and Urban-Rural Income Gap. China Rural Observation, 4, 37-46, 96.

Zimmerman, D. (1992). Regression toward Mediocrity in Economic Stature. American Economic Review, 82, 409-429. 